\title{
Teaching Team And Teaching Quality
}

\author{
Youqing Ding \\ College of Mechanical and Power Engineering \\ Chongqing university of science \& technology \\ Chongqing, China \\ dingyouqing@msn.com
}

\author{
Ning Xian \\ College of Foreign languages \\ Chongqing university of science \& technology \\ Chongqing, China \\ Xianning688@hotmail.com
}

\begin{abstract}
In recent years, colleges and universities pay more and more attention to the improving and strengthening of the quality of education and teaching. The concept of "teaching and quality is the life of a university" has been put forward as the core idea of running a school. The priority has been given to the promotion of the teaching reform and the betterment of teaching quality in the reform and development of colleges and universities. While the construction of academic teams should be strengthened, more attention should also be paid to the exploration and practice of the construction of teaching teams. This paper analyzes the problems existing in the teaching of the School of Mechanical and Power Engineering of Chongqing University of Science and Technology and puts forward a plan for the construction of teaching teams and illustrates the pivotal function of teaching teams in the construction of quality engineering.
\end{abstract}

Keywords- teaching team; quality engineering; management and operation component;

\section{PREFACE}

In the past few years, based on the research of the demand of the talent market and undergraduate programs, School of Mechanical and Power Engineering set the reform of curriculum system and teaching content as the core of the curriculum construction. Focusing on the teaching team, the logic structures of curriculums for undergraduates has been strengthened through the constructions of group courses, exquisite courses, key courses, web-based courses, textbook and the evaluation of training program, curriculum. The curriculum systems have been optimized and the teaching content has been renewed. The curriculum systems with the characteristics of applied undergraduate have been formed. However, the teaching team has the following problems in operation: (1)Teaching and research activities fail to reach its full swing and play its due role. At present, one third of the research activities involve passing on the documents or making announcements, while another one third go as a mere formality without any substance. As the basic teaching unit, the department established according to the discipline and curriculum is expected to carry out teaching academic research at grass-roots level and undertake the responsibility of teaching activities and teaching research duties as well. Nevertheless, its function has not been tapped into fully and effectively in the course of the actual operation and its development lags behind the pressing demands of the teaching reform. (2)The application and completion of
Education Reform Projects is mainly conducted on an individual basis, which lacks the necessary discussion, research and collective implementation of the projects within a team which has the same teaching background. Therefore, the project results may not be comprehensive and practical enough. The collective experience and wisdoms of teachers are paramount in the reform of teaching, while the lack of sense of collaboration and academic exchange among the teachers serves right as a hurdle making it difficult to promote the teaching reform effectively. (3) The selection of textbooks is mostly individual behavior, which indicates such teaching materials may not be highly consistent with the program and suitable for students. (4)There is no involvement of responsible experts who are expected to organize the discussion of the specific curriculum syllabus and its implementation in the experiment and teaching process. Sometimes teachers carry out their teaching processes at will. (5) Curriculum arrangement can never be an easy job. With the implementation of the post reform, when the teacher has completed considerable amount of work stipulated by the post, he or she in most cases is unwilling to undertake extra workload since his or her workload is full. Teachers from other related courses have to be found to teach the course, which may influence the teaching quality to a certain extent.

With the increase of the diversified needs and flexibility in obtaining knowledge on the students' part and deepening of teaching content, the traditional teaching mode lacking communication and collaboration among teachers is no longer able to adapt to the contemporary teaching requirements, and at the same time it is unlikely to achieve some breakthroughs in the field of theoretical teaching, practical teaching, and the integration of teaching and research. Thus, the establishment and enhancement of a highly effective teaching team model is the key to the practical implementation and effective promotion of the teaching reform in an endeavor to boost the teaching quality and teaching effect fundamentally.

\section{THE ESTABLISHMENT OF THE TEACHING TEAM}

At present, the School of Mechanical and Power Engineering has three undergraduate majors: mechanical design and automation, mechanical and electronic engineering and thermal energy and power engineering. 
There are 85 full-time teachers who assume 128 courses open to 41 majors with the workload of thousands of class hours for each semester. After careful investigation and discussion, teams are set up in the following manner:

Teaching teams are established based on the principle of the category of the curriculum belongingness. Each of the teachers can participate in different teams according to their courses they take. One course belongs to only one team and each teacher must attend at least one teaching team. As for professional basic courses and public courses, their teaching teams are composed of all the teachers who get involved in the teaching of these courses and the teams are named after each specific course. In terms of professional courses, their teams are set up mainly based on the professional orientation of the courses. There should be certain association and relativity among the courses in a teaching team. As for field trip courses and practice courses, there are no separate teaching teams for them. A team leader is chosen to take charge of the each teaching team. The team leader should be one of the leading teachers with the title of associate professor or above. The team leader is the person who takes primary responsibility for the teaching quality of curriculum in the team and conducts the overall planning for the curriculum construction of the team (including organizing the formulation of course syllabus, teaching objectives and examination requirements, setting examination questions, the compilation and publication of teaching plans and textbooks). Meanwhile, the team leader is supposed to take the charge of organizing the training of the course teachers in the team, carrying out teaching research (including discussion and communication on teaching content, teaching methods, organizing the observing of classroom teaching and guidance, research on the application of projects, research and development of teaching equipment and the writing of teaching research papers) and is responsible for the echelon construction of teachers of the whole team so as to ensure the quality of teaching.

\section{THE OPERATION AND MANAGEMENT OF THE TEACHING TEAMS}

The orderly operation and smooth pushing forward of the teaching team depends on whether there are relevant policy support and guarantee of the institutional environment suitable for the development of teaching teams.

《 Measures on the construction and management of teaching team 》 (Interim Version ) has been formulated in pursuit of tapping into the full potential and making the best use of teaching teams in the process of teaching. Members of teaching teams share the same or similar background knowledge and skills. There is no division of the rank among one another. They work together to accomplish the team goals through imparting knowledge to students. The head of the teaching team is responsible for the effective operation of the team and carrying out of the teaching research. The team leader also takes the lead in facilitating the progress of both the team and individuals based on the respect for the rights and personalities of individual members of the team through promoting the full communication and exchange among team members. In the post system, the team leader can shake off some other work duties so as to focus more energy on the work of team construction. Every member in the teaching team assumes a certain amount of teaching task, but also takes a role in the team enjoying a right and an obligation as well and plays his or her unique role in the team. The School and the Department provide service work for the teams. In any case, a teaching team must finish its teaching task.

\section{THE FUNCTION OF THE CONSTRUCTION OF TEACHING TEAMS IN QUALITY ENGINEERING}

The construction of teaching teams plays an important role in quality engineering mainly in the following aspects:

1 . The construction of teaching teams can improve the overall standards of teaching in the university. The establishment of teaching teams promotes the implementation and advance of the goal of the teaching reform , optimizes course systems and teaching content and solves the problems of inconsistency between the talent cultivation system and teaching modes and methods. Team members can fulfill their respective potential in the team, which can enhance the overall education effect. Through the establishment of teaching teams, the implementation of each course has been fully discussed, which is the embodiment of collective wisdom and can improve the quality of teaching. In the post reform, teachers have to further clarify their responsibilities and obligations.

2. Teaching and research activities can be carried out more fully and more specifically. Activities of teaching teams are teaching and research activities in real sense and can be more targeted led by the team lead. A department often has multiple teaching teams with their activities independent of each other and combined as well with each other without the time and place restriction.

3. Individual behavior of declaring projects will become collective undertaking of team declaration. The teaching reform projects can be more practical and effective after the team discussion, research and implementation. At the same time, a clear focus can be put on the university's key supporting curriculum and teaching reform direction and the cut-in point can be exactly located. The leading role of teaching teams can be fully played in the teaching reform.

4. Teaching teams can be conducive to the cultivation of high quality teachers. Teaching teams emerge in the backdrop of the urgent need of teaching reform and improving the teaching quality. At present, teachers focus their wit and energy mainly on scientific research and they are short of good teaching atmosphere of $t$ organized teaching cooperation and exchanges to improve the quality of teaching. Therefore, the establishment of teaching teams, on the one hand, is in line with the need of contemporary teaching reform; on the other hand, the teaching team provides a platform for the development of the academically- 
accomplished team leaders who are the passionate young and middle-aged backbone in the teaching reform. Thus, the overall teaching quality of the teaching staff can be improved in this process and at the same time, unique characteristics in teaching can be formed.

\section{SUMMARY}

At present, the construction of teaching teams has not drawn enough attention and concern of many universities; teachers also fail to put sufficient time and efforts into teaching research and teaching reform, which has something to do with the policy orientation of highlighting research and ignoring teaching prevailing in colleges and universities in recent years. Colleges and universities are expected to put the construction of teaching teams in an important strategic position of survival and development from a strategic and overall perspective, to establish and improve the management and operation mechanism for the independent and good operation of the teaching teams, to build and run the teams according to the teaching rules.

The construction of teaching teams can be beneficial to the effective integration of teaching resources, the strengthening and promotion of the exchange among teachers and all-around cultivation of students through collective efforts of the team. It is also conducive to the improvement of the university teaching level, the effective operation of the teaching and research activities, the training and cultivation of high quality teachers, the handling of complex teaching problems and the enhancement of the quality of talent cultivation.

The construction of college teaching teams is a systematic project which entails not only the establishment and improvement of the internal incentive mechanism but also the vigorous investment of external resources, the support of institutional environment and cultural atmosphere.

\section{Acknowledgment}

It is the Foundation Project: Higher Education Research

Project of Chongqing University of Science and Technology.

\section{REFERENCES}

[1] Ministry of finance, Ministry of Education, "On the implementation of the undergraduate teaching quality and teaching reform project of opinions", 2007 (references).

[2] Ministry of Education, "The Ministry of education on strengthening the construction of higher education 30 opinions", 2011.

[3] Berg, "The higher education quality and accountability", 2010, pp. 27-55.

[4] LIU Yan-ni, Deng Jun, the National Natural Science Foundation in the cultivation of high-level personnel play an important role [J], National Natural Science Foundation of China, 2009 (5)

[5] Li Jianhui, On the theory of motivation in the Distribution System Reform in Universities [J], Zhangzhou Teachers College, 2003 (3) 